\title{
Sensitive quantitative assay for point mutations in the rat $H-r a s$ gene based on single nucleotide primer extension
}

\author{
YOSHIHISA YANO ${ }^{1}$, TOMOHIRO YANO ${ }^{3}$, ANNA KINOSHITA ${ }^{2}$, AI MATOBA ${ }^{1}$, TADAYOSHI HASUMA ${ }^{1}$, \\ HIDEKI WANIBUCHI $^{2}$, KEIICHIROU MORIMURA ${ }^{2}$, SHUZO OTANI $^{1}$ and SHOJI FUKUSHIMA ${ }^{2}$ \\ Departments of ${ }^{1}$ Biochemistry, and ${ }^{2}$ Pathology, Osaka City University Medical School, Osaka; \\ ${ }^{3}$ Project for Complementary Medicine, The National Institute of Health and Nutrition, Tokyo, Japan
}

Received March 22, 2010; Accepted May 31, 2010

DOI: $10.3892 /$ etm_00000103

\begin{abstract}
Point mutations in oncogenes and tumor suppressor genes occur at early stages in the carcinogenic process. Point mutations in ras family oncogenes are the most common mutational events in several types of human cancer, and are available as molecular markers for the detection of cancer cells in carcinogenicity bioassay systems as well as in clinical samples. Although several techniques are utilized to detect point mutations in carcinogenicity bioassay systems, the sensitivity is too low to determine a small number of mutations. In order to overcome the disadvantage and to sensitively determine gene mutation rates for in vivo carcinogenicity bioassays of presumptive carcinogens, we established a Thermosequenase Cycle End Labeling (TCEL) method, a sensitive approach based on single nucleotide primer extension. One of the characteristics of the method is a high sensitivity of 1:100,000, ten times the sensitivity of the mutant allele-specific amplification now commonly employed. Using TCEL, we here quantified $\mathrm{H}$-ras mutations in the livers of rats treated with a genotoxic carcinogen, 2-amino-3,8-dimethylimidazo[4,5-f]quinoxaline. Our findings suggest that this method may be applied for many genetic targets as a component in vivo.
\end{abstract}

\section{Introduction}

Many of the genetic alterations that occur during cancer development include point mutations in oncogenes and tumor suppressor genes. Changes in ras family oncogenes at codons 12, 13 and 61 are some of the most common mutational events in human carcinogenesis (1). Such point mutations are used as molecular markers for the detection of cancer cells in clinical

Correspondence to: Dr Tomohiro Yano, Project for Complementary Medicine, The National Institute of Health and Nutrition, 1-23-1 Toyama, Shinjuku-ku, Tokyo 162-8636, Japan

E-mail: ya.tomohiro@gmail.com

Key words: H-ras, sensitive quantitative assay for point mutation, Thermosequenase Cycle End Labeling method, 2-amino-3,8dimethylimidazo[4,5- $f$ ]quinoxaline samples. In addition, the same approach may be utilized in carcinogenicity bioassays.

Several techniques are now available to detect point mutations. Single-strand conformation polymorphism (2), RNase protection assay (3), denatured gel electrophoresis (4) and allele-specific oligonucleotides (5) are most commonly used for this purpose. However, when the level of the mutant sequence in a mixed population of alleles is $5 \%$ or less, these methods are not applicable. Mutant allele-specific amplification (MASA) (6-8) is a more powerful method that is used for detecting a small number of mutant alleles in a large number of normal alleles, and in one case proved capable of detecting one CC to TT mutation among $10^{7}$ wild-type genes in mitochondrial DNA (9). However, the reported sensitivity of this method is frequently $10^{-4}$ or less (10-12). Moreover, when using this assay, it is necessary to optimize PCR conditions such as the cycle number, annealing temperature and $\mathrm{Mg}^{2+}$ concentration for each primer sequence to avoid mismatched amplification $(13,14)$.

Heterocyclic amine mutagens are formed in fried or grilled meats as products of protein pyrolysis or Maillard reactions $(15,16)$. The human daily intake of one of these, 2-amino-3, 8-dimethylimidazo[4,5-f]quinoxaline (MeIQx), is estimated to be $0.2-2.6 \mu \mathrm{g} /$ person (17). MeIQx can be detected in the urine of healthy volunteers after eating cooked meat (18-20), and MeIQx-DNA adducts have been found in kidney and colon tissues in humans (21). In rats, MeIQx induces DNA adduct formation in the liver (22) and the development of hepatocellular carcinomas with treatment at high doses (23).

In the present study, we established a highly sensitive quantitative method for the detection of the $\mathrm{G}$ to $\mathrm{T}$ base substitution mutations in codon 12 of the rat $\mathrm{H}$-ras gene in order to improve in vivo carcinogenicity bioassays of presumptive carcinogens. The sensitivity of the assay is $10^{-5}$, which means detection of one mutation in $10^{5}$ wild-type genes. Using this method, we here examined H-ras mutations in the liver DNA of rats treated with the genotoxic carcinogen, MeIQx.

\section{Materials and methods}

Preparation of a mutant plasmid. To generate a plasmid with a portion of the rat H-ras gene containing codon 12, a 463-bp fragment from exon 1 , amplification was performed by PCR using two 


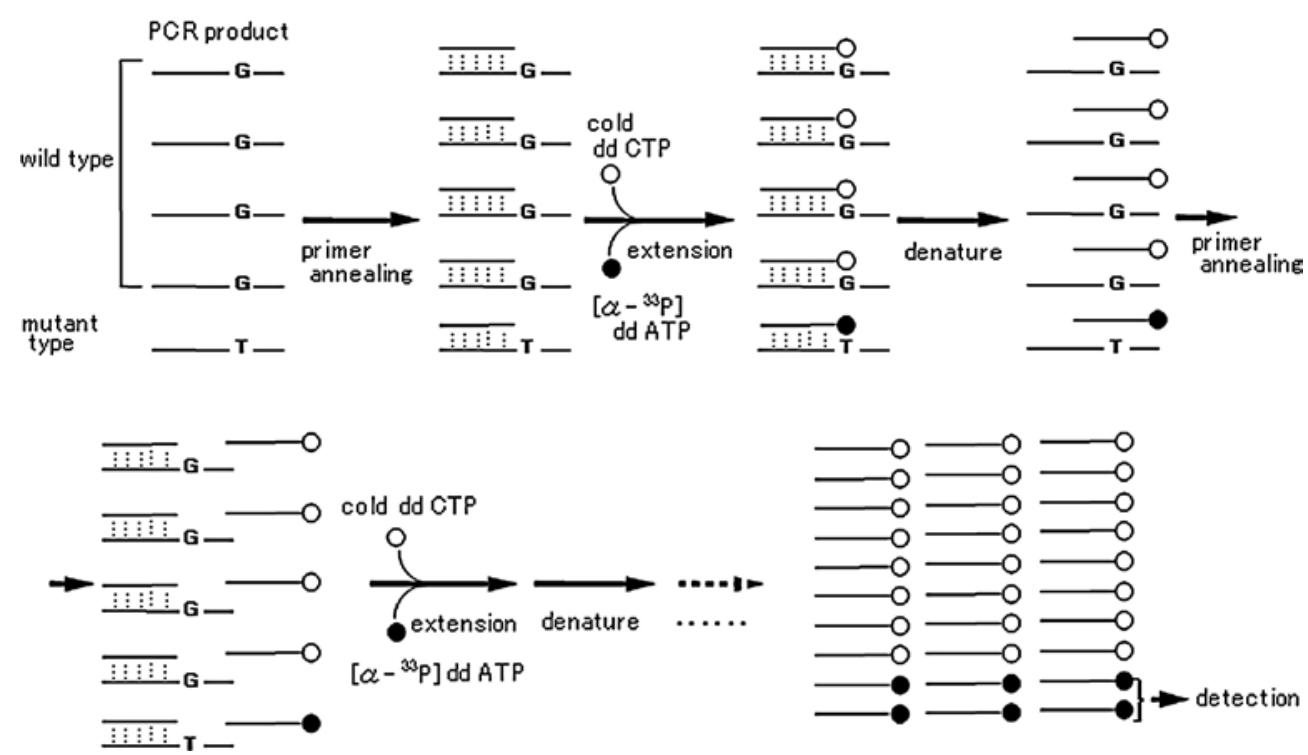

Figure 1. Principle of the Thermosequenase Cycle End Labeling (TCEL) assay.

primers (RHras-146S: 5'-CCACTGGCTTGCTTGCCTACT-3' and RHras317A: 5'-TTCCGGTAGGAGTCCTGCAA-3'), and the PCR product was subcloned into the SmaI site of the pKF18 vector (Takara Bio Inc., Shiga, Japan). A mutant standard with $\mathrm{G}$ to $\mathrm{T}$ at the second nucleotide of codon 12 was prepared using a Mutant-Super Express Km kit (Takara Bio Inc.), and the presence of the mutation was confirmed by DNA sequencing.

Preparation of standard DNA. To prepare the standard for calibration, plasmid DNA containing mutant H-ras at $10^{-2}$ to 0 was amplified by high fidelity PCR. Plasmid DNA ( 5 fmols) was amplified in a total volume of $100 \mu \mathrm{l}$ containing $50 \mathrm{pmol}$ each of the RHras-146S and RHras317A primers, $20 \mathrm{mM}$ Tris- $\mathrm{HCl}$ (pH 7.5), $0.2 \mathrm{mM}$ dNTPs, $1 \mathrm{mM} \mathrm{MgCl}_{2}, 7.5 \mathrm{mM}$ DTT, $2.5 \mu \mathrm{g}$ BSA, and 2 units KOD-Plus-DNA polymerase (Toyobo Co. Osaka, Japan). Following denaturation at $95^{\circ} \mathrm{C}$ for $3 \mathrm{~min}$, amplification was performed in a GeneAmp 9600 thermal cycler (Applied Biosystems, CA, USA) with the following protocol: 30 cycles for $30 \mathrm{sec}$ at $95^{\circ} \mathrm{C}, 30 \mathrm{sec}$ at $55^{\circ} \mathrm{C}$ and $60 \mathrm{sec}$ at $68^{\circ} \mathrm{C}$. After amplification, to remove the PCR primers and dNTPs completely, the PCR products were gel-filtrated on ProbeQuant G-50 Micro Columns (Amersham Biosciences Co., NJ, USA), incubated with 10 units exonuclease I and 2 units shrimp alkaline phosphatase (Amersham Biosciences Co.) at $37^{\circ} \mathrm{C}$ for $30 \mathrm{~min}$, and then purified using a GFX PCR DNA Purification kit (Amersham Biosciences).

Thermosequenase Cycle End Labeling (TCEL). The PCR product $(100 \mathrm{fmol})$ was used as a template for TCEL reactions in a total volume of $10 \mu \mathrm{l}$ containing $26 \mathrm{mM}$ Tris- $\mathrm{HCl}(\mathrm{pH} 9.5)$, $6.51 \mathrm{mM} \mathrm{MgCl}_{2}, 2 \mathrm{pmol}$ of the primer for mutation detection (RHrasc12bA: 5'-GGGCACTCTTTCCCACGCCT-3'), 30 pmol ddCTP, 70 fmol ddATP, 70 fmol ddGTP, 70 fmol ddTTP, $30 \mathrm{fmol}\left[\alpha^{-33} \mathrm{P}\right] \mathrm{ddCTP}$ or $\left[\alpha^{-3} \mathrm{P}\right] \mathrm{ddATP}(1,500 \mathrm{Ci} /$ mmol) (Amersham Biosciences), 0.5 units Thermosequenase (Amersham Biosciences) and 10\% DMSO. Non-labeled dideoxynucleotides were added to prevent a wrong addition of labeled dideoxynucleotides at the 3'-end of a detection primer. TCEL reactions were performed in a GeneAmp 9600 thermal cycler with the following protocol: 50 cycles for $15 \mathrm{sec}$ at $95^{\circ} \mathrm{C}$ and $15 \mathrm{sec}$ at $55^{\circ} \mathrm{C}$. The reaction products were concentrated with a vacuum concentrator down to a $1 / 10$ volume, mixed with $5 \mu \mathrm{l}$ of deionized formamide containing $0.05 \% \mathrm{BPB}$ and $0.05 \% \mathrm{XC}$, heated at $95^{\circ} \mathrm{C}$ for $2 \mathrm{~min}$, placed on ice and loaded on a $12 \%(\mathrm{~W} / \mathrm{V})$ denaturing polyacrylamide gel containing $7 \mathrm{M}$ urea. Gels were run at 1,000 V constant voltage for $3.5 \mathrm{~h}$. The amounts of ${ }^{33} \mathrm{P}$-labeled primers were measured using a bio-imaging analyzer (BAS 2500; Fuji Photo Film Co., Tokyo, Japan).

Animals and chemicals. MeIQX (purity 99.9\%) was purchased from the Nard Institute (Nishinomiya, Japan). A total of 110 male 21-day-old F344 rats [70 for mutation frequency analysis, 20 for the analysis of cell proliferation using 5-bromodeoxyuridine (BrdU) labeling and 20 for apoptosis detection] were obtained from Charles River Japan, Inc. (Atugi, Japan). The animals were housed in an animal facility room maintained at a 12-h light/dark cycle at a constant temperature of $25 \pm 1^{\circ} \mathrm{C}$ and a relative humidity of $55 \pm 5 \%$ and observed daily.

Animal experiment 1. Seventy rats were employed in this experiment for measurement of $\mathrm{H}$-ras mutation frequency. They received MeIQx at doses of 0 (group 1, control), 0.001 (group 2), 0.01 (group 3), 0.1 (group 4), 1 (group 5), 10 (group 6) and 100 ppm (group 7) in a powdered basal diet for 1 or 2 weeks, continuously. The MeIQx diets were prepared by Oriental Yeast Co. (Tokyo, Japan), and the concentration in each diet was confirmed by HPLC. After 1-2 weeks of MeIQx administration, all rats in each group were sacrificed under anesthesia with diethyl ether, and the livers were quickly removed and frozen in liquid nitrogen for molecular assessment. Rat liver genomic DNA was prepared with a QIAamp DNA Mini kit according to the manufacturer's instructions (Qiagen, Hilden, Germany), and $1 \mu \mathrm{g}$ of genomic DNA was amplified by high fidelity PCR using KOD-Plus-DNA polymerase. 

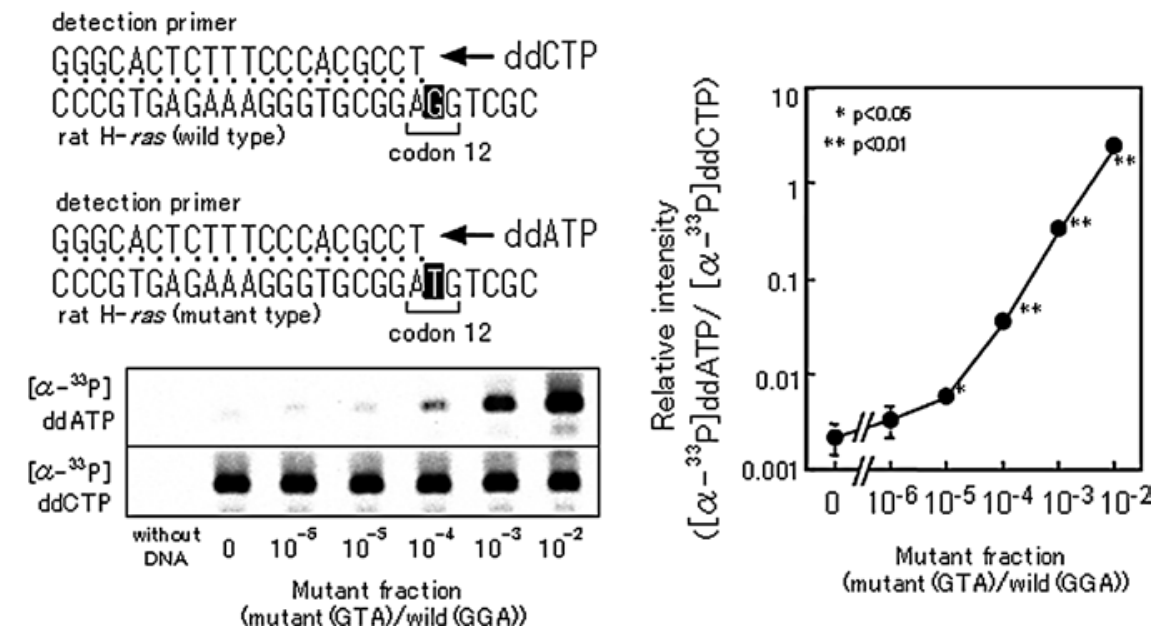

Figure 2. Standard curve for the TCEL assay. Data are mean \pm SD of the replicates, although the standard deviation is too small to be discerned. "p $<0.05 \mathrm{vs}$. the mutant fraction $0 ;{ }^{* *} \mathrm{p}<0.01 \mathrm{vs}$. the mutant fraction 0 .

Animal experiment 2. Forty rats were used in the experiment for the immunohistochemical demonstration of BrdU labeling and apoptosis. They were fed an MeIQx diet at doses of 0, 1, 10 and 100 ppm continuously for 2 weeks. Twenty rats each were sacrificed for BrdU and apoptosis measurement; in the former case $1 \mathrm{~h}$ after receiving an i.p. injection of $\mathrm{BrdU}(100 \mathrm{mg} /$ $\mathrm{kg}$ body weight). At autopsy, livers were excised and $3-\mu \mathrm{m}$ slices were cut with a razor blade and fixed in $10 \%$ buffered formalin solution for subsequent immunohistochemical identification of BrdU-positive cells. After deparaffinization, $\mathrm{H}_{2} \mathrm{O}_{2}$ pre-treatment and microwaving, liver sections were treated sequentially with normal horse serum, anti-mouse BrdU antibody (Dako Japan Co., Ltd., Tokyo, Japan; 1:1000) at $4^{\circ} \mathrm{C}$ overnight, horse anti-mouse $\operatorname{IgG}(1: 400)$ for $30 \mathrm{~min}$ and the avidin-biotin peroxidase complex reagent for $30 \mathrm{~min}$. Analysis of $~ 5,000$ hepatocytes in each sample was performed, and BrdU labeling indices for rat liver were calculated as percentages of positively stained cells among $\sim 1,000$ hepatocytes. To detect apoptotic cells in sections of fixed, paraffin-embedded tissue, the TUNEL method was applied using an ApopTag Peroxidase kit for in situ apoptosis detection according to the manufacturer's instructions (Intergen Co., NY, USA).

Statistical analysis. Comparisons of the observed values for statistically significant differences were performed using the Student's t-test, with the aid of the StatView ver. 5.0 statistical package (Abacus Concepts, Inc., CA, USA).

\section{Results}

The principle of the TCEL method. The principle of the TCEL method based on single nucleotide primer extension is as follows: i) a detection primer is synthesized to end at one nucleotide $5^{\prime}$ of the mutation being probed for in the PCR product; ii) a cycle sequencing reaction is performed using Thermosequenase and a mixture of the non-labeled terminator (ddCTP) and mutant ${ }^{33} \mathrm{P}$-labeled terminator $\left(\left[\alpha-{ }^{33} \mathrm{P}\right] \mathrm{ddATP}\right)$, so that extension by a single nucleotide occurs with the primer by either normal or mutant terminators according to the mutation rate (Fig. 1). Fig. 2 shows a representative standard curve for

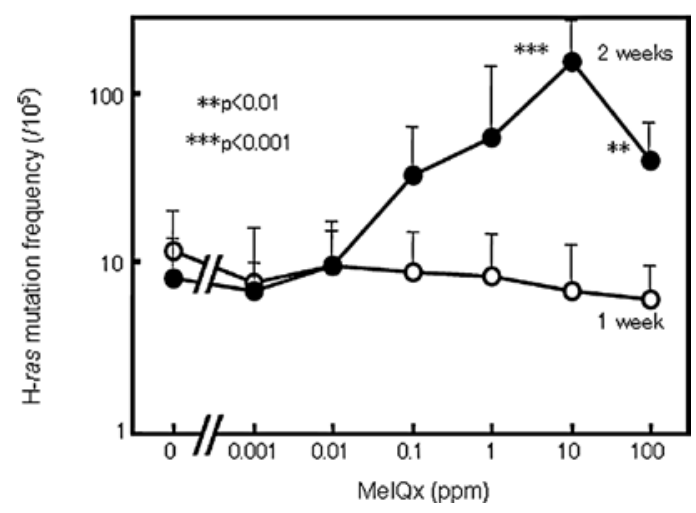

Figure 3. H-ras mutation frequency in the liver of rats treated with MeIQx for 1 week $(\circ)$ and 2 weeks $(\bullet) .{ }^{* *} \mathrm{p}<0.01$ vs. the 0 ppm group; ${ }^{* * *} \mathrm{p}<0.001 \mathrm{vs}$. the 0 ppm group.

the TCEL assay, which allows detection of one mutant allele among $10^{5}$ normal alleles.

Animal experiments. The frequency of H-ras mutations detected by TCEL assay in the rat livers of all groups receiving from 0.001 to $100 \mathrm{ppm}$ of MeIQx in the diet for 1 week did not differ from the control value (Fig. 3). On the other hand, in the livers of rats treated with MeIQx for 2 weeks, the H-ras mutation frequency was elevated generally in a dose-dependent manner with statistical significance at 10 and $100 \mathrm{ppm}$ (Fig. 3). However, the level in the group treated with 100 ppm MeIQx was non-significantly lower than the level in the group treated with 10 ppm (Fig. 3). Liver BrdU and apoptotic indices for the groups receiving 1 and 10 ppm MeIQx did not differ from the controls (Fig. 4), in contrast to the significant elevation apparent in the 100-ppm MeIQx group.

\section{Discussion}

The MASA method is one of the most highly sensitive methods to detect mutation alleles in the presence of a very large excess of normal alleles (6-8). It is based on the inability of Taq DNA polymerase to elongate a primer when the $3^{\prime}$ end does not match the template DNA. However, in many cases, substantial 

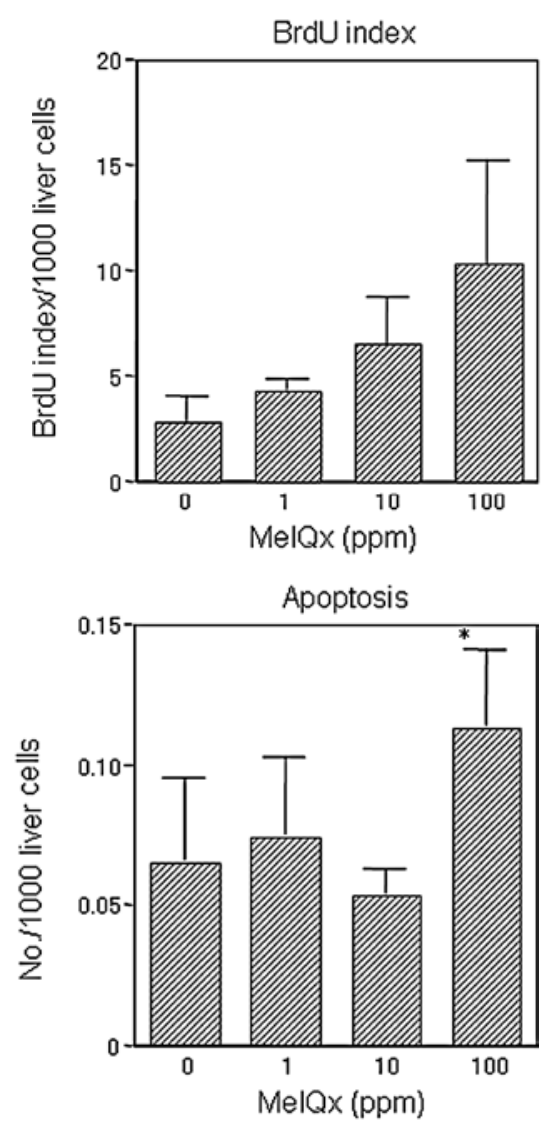

Figure 4. BrdU indices and TUNEL-positive cells in the livers of rats treated with MeIQx for 2 weeks. "p $<0.05$ vs. the 0 ppm group.

modification is necessary to achieve reliable results $(13,14)$. We previously examined the sensitivity, quantitativeness and reproducibility of the MASA method for the detection of rat $\mathrm{H}$-ras mutations, but we did not obtain satisfactory results. In our investigation, the limit of detection for MASA was one mutant allele for a background of thousands of normal alleles (data not shown), and the sensitivity level was equal to that previously reported (10).

In the present study, we established a highly sensitive quantitative method, the TCEL assay, based on single nucleotide primer extension and established a quantitative range of 1 in $10^{-2}$ to $10^{-5}$. To confirm the reliability, blind tests with standard samples were performed by two workers independently, and the obtained results were reliable (data not shown). One of the purposes of the present investigation was to check the feasibility of adding somatic mutations to parameters for assessment of in vivo carcinogenicity. Using our method, we quantified $\mathrm{H}-$ ras mutations in the livers of rats treated with a genotoxic carcinogen, MeIQx. Thus, while the administration of MeIQx for 1 week did not influence the mutation frequency, presumably since this does not provide sufficient time for fixation, in line with previous observations (8), the treatment with 10 and 100 ppm MeIQx for 2 weeks induced appreciable $\mathrm{H}$-ras mutations. When administration of MeIQx for 2 weeks was repeated, similar results were obtained (unpublished data). It has been reported that a high dose of MeIQx causes a decrease in the transformation rate in the in vitro cell transformation assay using $\mathrm{C} 3 \mathrm{H} / \mathrm{M} 2$ fibroblasts (24). In the present investigation, a significant elevation in liver apoptotic and
BrdU indices in the 100-ppm MeIQx group was found and this partially explains the lack of dose dependence, with a decrease in the mutation rate in the high dose group resulting from the cytotoxicity of MeIQx, while the BrdU index reflects compensatory regeneration.

In summary, we developed a highly sensitive, quantitative and reproducible method for detecting small amounts of mutant H-ras DNA. Furthermore, our method may offer another approach to the assessment of in vivo carcinogenicity. Moreover, it should be applicable to various genetic targets with appropriate simple changes in primer sequences. The technique may also be used for the analysis of clinical samples and may provide a useful tool for cancer screening or early diagnosis of human cancer.

\section{Acknowledgements}

This study was supported by a grant from the Japan Science and Technology Corporation, included in the Project of Core Research for Evolutional Science and Technology (CREST) and Regional Science Promotion Program (RSP). We thank Dr Shinji Hirotsune for the help and support during the development of the methodology.

\section{References}

1. Sistonen L and Alitalo K: Activation of c-ras oncogenes by mutations and amplification. Ann Clin Res 18: 297-303, 1986.

2. Orita M, Suzuki Y, Sekiya T, et al: Rapid and sensitive detection of point mutations and DNA polymorphisms using the polymerase chain reaction. Genomics 5: 874-879, 1986.

3. Winter E, Yamamoto F, Almoguera C, et al: A method to detect and characterize point mutations in transcribed genes: amplification and overexpression of the mutant c-Ki-ras allele in human tumor cells. Proc Natl Acad Sci USA 82: 7575-7579, 1985.

4. Myers RM, Lumelsky N, Lerman LS, et al: Detection of single base substitutions in total genomic DNA. Nature 313: 495-498, 1985.

5. Conner BJ, Reyes AA, Morin C, et al: Detection of sickle cell beta $\mathrm{S}$-globin allele by hybridization with synthetic oligonucleotides. Proc Natl Acad Sci USA 80: 278-282, 1983.

6. Ehlen T and Dubeau L: Detection of ras point mutations by the polymerase chain reaction using mutation-specific, inosine-containing oligonucleotide primers. Biochem Biophys Res Commun 160: 441-447, 1989.

7. Ichikawa T, Yano Y, Uchida M, et al: The activation of K-ras gene at an early stage of lung tumorigenesis in mice. Cancer Lett 107: 165-170, 1996.

8. Yano T, Yuasa M, Murakami A, et al: The detection of chemically initiated cells having the mutation of K-ras gene at an early stage of lung carcinogenesis in mice. Anal Biochem 244: 187-189, 1997.

9. Kawasaki K, Suzuki T, Ueda M, et al: CC to TT mutation in the mitochondrial DNA of normal skin: relationship to ultraviolet light exposure. Mutat Res 22: 35-43, 2000.

10. Takeda S, Ichii S and Nakamura Y: Detection of K-ras mutation in sputum by mutant-allele-specific amplification (MASA). Hum Mutat 2: 112-117, 1993.

11. Liang TJ, Hasegawa K, Munoz SJ, et al: Hepatitis B virus precore mutation and fulminant hepatitis in the United States. A polymerase chain reaction-based assay for the detection of specific mutation. J Clin Invest 93: 550-555, 1994.

12. Horikoshi T, Lenz HJ, Danenberg K, et al: Quantitative determination of the ratio of mutated to normal ras genes in the blood of leukemia patients by allele-specific PCR. Leuk Res 18: 693-702, 1994.

13. Etoh $\mathrm{T}$, Ueo $\mathrm{H}$, Inoue $\mathrm{H}$, et al: Clinical significance of $\mathrm{K}$-ras mutations in intraoperative tumor drainage blood from patients with colorectal carcinoma. Ann Surg Oncol 8: 407-412, 2001.

14. Hashimoto T, Kobayashi Y, Ishikawa Y, et al: Prognostic value of genetically diagnosed lymph node micrometastasis in non-small cell lung carcinoma cases. Cancer Res 60: 6472-6478, 2000. 
15. Felton JS and Knize MG: Occurrence, identification, and bacterial mutagenicity of heterocyclic amines in cooked food. Mutat Res 259: 205-217, 1991.

16. Snyderwine EG: Some perspectives on the nutritional aspects of breast cancer research. Food-derived heterocyclic amines as etiologic agents in human mammary cancer. Cancer 74: 1070-1077, 1994.

17. IARC Working Group on the evaluation of carcinogenic risk to humans: MeIQx (2-amino-3,8-demethylimidazo[4,5- $f$ ]quinoxaline). In: IARC Monographs on the Evaluation of Carcinogenic Risks to Humans - Some Naturally Occurring Substances: Food Items and Constituents, Heterocyclic Aromatic Amines and Mycotoxins. Vol. 56. Armstrong B (ed). IARC Publisher, Lyon, pp221-228, 1993

18. Murray S, Gooderham NJ, Boobis AR, et al: Detection and measurement of MeIQx in human urine after ingestion of a cooked meat meal. Carcinogenesis 10: 763-765, 1989.

19. Ushiyama H, Wakabayashi K, Hirose M, et al: Presence of carcinogenic heterocyclic amines in urine of healthy volunteers eating normal diet, but not of inpatients receiving parenteral alimentation. Carcinogenesis 12: 1417-1422, 1991.
20. Tannenbaum SE, Stillwell WG, Ji H, et al: MeIQx (2-amino-3,8demethylimidazo $[4,5-f]$ quinoxaline): metabolism in humans and urinary metabolites in human populations. In: Heterocyclic Amines in Cooked Foods, Possible Human Carcinogens. Asamson RH, Gustafsson JA, Ito N, Nagao M, Sugimura T, Wakabayashi K and Yamazoe Y (eds). Princeton Scientific Publishing Co. Inc., Princeton, pp197-206, 1993.

21. Totsuka Y, Fukutome K, Takahashi M, et al: Presence of N2-(deoxyguanosin-8-yl)-2-amino-3,8-dimethylimidazo[4,5-f] quinoxaline (dG-C8-MeIQx) in human tissues. Carcinogenesis 17: 1029-1034, 1996.

22. Yamashita K, Adachi M, Kato S, et al: DNA adducts formed by 2 -amino-3,8-dimethylimidazo[4,5-f]quinoxaline in rat liver: dose-response on chronic administration. Jpn J Cancer Res 81: 470-476, 1990

23. Kato $\mathrm{T}$, Ohgaki $\mathrm{H}$, Hasegawa $\mathrm{H}$, et al: Carcinogenicity in rats of a mutagenic compound, 2-amino-3,8-dimethylimidazo[4,5- $f]$ quinoxaline. Carcinogenesis 9: 71-73, 1998

24. Pfau W, Martin FL, Cole KJ, et al: Heterocyclic aromatic amines induce DNA strand breaks and cell transformation. Carcinogenesis 20: 545-551, 1999. 